\title{
0 ciclo da dependência às rendas petrolíferas em municípios do norte fluminense
}

\author{
Rosélia Piquet \\ Ronaldo Costa da Silva ${ }^{1}$
}

\begin{abstract}
Resumo
O artigo avalia os impactos das rendas petrolíferas nos orçamentos de municípios selecionados do norte fluminense, especialmente no que diz respeito à dependência, partindo-se de uma pesquisa realizada no ano de 2011, que levou em consideração estudos socioeconômicos elaborados pelo TCE-RJ.
\end{abstract}

Palavras-chave: rendas petrolíferas; orçamento municipal; Norte Fluminense

\begin{abstract}
The article evaluates the impacts of oil revenues in the budgets of selected cities in the north of the state, especially with regard to dependence, starting with a survey conducted in 2011, which took into account socioeconomic studies prepared by TCE-RJ.
\end{abstract}

Keywords: oil revenues; municipal budget; north of Rio de Janeiro state

\section{Introdução}

Com as mudanças legais aprovadas pelo Congresso Nacional a partir do final da década de $1990,{ }^{2}$ os municípios situados ao norte do Estado do Rio de Janeiro foram favorecidos em seus orçamentos com as crescentes receitas advindas da exploração do petróleo na Bacia de Campos. A partir de então, os royalties e as participações especiais tornaram-se rubricas relevantes nesses orçamentos, em alguns casos, chegando a responder por mais de $70 \%$ do conjunto das receitas orçamentárias.

\footnotetext{
1 Rosélia Piquet é doutora em Economia pela UFRJ, professora titular da UFRJ, coordenadora do Mestrado Profissional em Planejamento Regional e Gestão de Cidades da Universidade Candido Mendes - Campos (UCAM). ropiquet@terra.com.br

Ronaldo Costa da Silva é mestre em Planejamento Regional e Gestão de Cidades pela Universidade Cândido Mendes - Campos (UCAM). Vereador do Município de Quissamã (RJ), professor do curso de Administração da Faculdade Metropolitana São Carlos - Quissamã (FAMESC), procurador do Município licenciado. ronaldo.costa307@gmail.com 
Diante de uma alteração fiscal substancial como esta, há que se investigar qual a influência dessas compensações petrolíferas sobre o comportamento orçamentário nesses municípios. Estariam a doença holandesa ou a maldição da abundância de recursos naturais ${ }^{3}$ afetando os orçamentos fiscais dos municípios do norte do Estado do Rio de Janeiro? Estaríamos diante de municípios com pouca capacidade de investimento e incapazes de manter seus serviços básicos sem o recebimento de royalties e das participações especiais? É fato que toda receita tende a criar sua própria despesa (Lei de Say Fiscal), dado que a expansão de serviços públicos mediante o uso das rendas petrolíferas inevitavelmente eleva os gastos com custeio para mantê-los (Prado, 2001); no entanto, em não havendo um controle da qualidade desses gastos, eles podem inviabilizar as finanças municipais a curto e médio prazo. São questões a serem enfrentadas neste trabalho.

O objetivo deste artigo, portanto, é avaliar os impactos das rendas petrolíferas nos orçamentos de municípios selecionados do norte fluminense, especialmente no que diz respeito à dependência, partindo-se de uma pesquisa realizada nos anos de 2011 e 2012 (Costa da Silva, 2012), que levou em consideração os estudos socioeconômicos publicados anualmente pelo Tribunal de Contas do Estado do Rio de Janeiro (TCE-RJ) dos municípios escolhidos, no período de 2000 a 2009. Com a atualização de dados contidos nesses estudos como: grau de investimento, comprometimento das receitas com custeio da máquina administrativa, autonomia financeira e outros que serão explicados na metodologia deste trabalho, será possível identificar o comportamento dos orçamentos nos últimos anos e as correspondentes conclusões.

\section{1 - Metodologia}

Os municípios selecionados para a pesquisa foram: Campos dos Goytacazes, Macaé, Rio das Ostras e São João da Barra. Esses municípios representam não só o maior conjunto populacional da região norte fluminense e os que mais receberam royalties e participações especiais no ano de 2013. O Município de Rio das Ostras, apesar de não pertencer geograficamente à região norte fluminense, consta da análise já que também se situa na Zona de Produção Principal para fins de recebimento de participações governamentais e, por fazer divisa com o Município de Macaé, abriga inúmeras empresas da área offshore. Suas condições orçamentárias assemelham-se aos demais municípios da região norte do Estado do Rio de Janeiro.

Optou-se pela análise comparativa entre os municípios selecionados e outros municípios do Estado do Rio de Janeiro não pertencentes à Zona de Produção Principal que, embora não sejam recebedores de grandes quantias de rendas petrolíferas, são possuidores de populações equivalentes aos da região norte fluminense. A ideia é compreender as possíveis diferenças no comportamento dos orçamentos fiscais e seus indicadores entre municípios que recebem e os que não recebem expressivas somas de royalties e participações especiais. Os municípios destacados para os estudos comparativos são: Belford Roxo, Volta Redonda, Resende e Piraí. 
Tabela 1

Valores nominais recebidos de royalties e participações especiais no ano de 2013 e população 2010.

\begin{tabular}{|l|c|c|}
\hline Beneficiários Ano 2013 & População & Royalties e PE em R\$ \\
\hline Campos dos Goytacazes & 463.731 & $1.309 .746 .088,07$ \\
\hline Belford Roxo & 469.332 & $10.700 .403,14$ \\
\hline Macaé & 206.728 & $517.249 .754,65$ \\
\hline Volta Redonda & 257.803 & $14.051 .356,65$ \\
\hline Rio das Ostras & 105.676 & $328.594 .034,86$ \\
\hline Resende & 119.769 & $13.125 .434,68$ \\
\hline São João da Barra & 32.747 & $227.032 .110,48$ \\
\hline Piraí & 26.314 & $10.184 .895,22$ \\
\hline Fontes: www.bge.gov.br e www.anp.gov.br. Tabulação dos autores com base em dados do IBGE (Censo 2010).
\end{tabular}

Tomou-se como base neste artigo os dados referentes à execução orçamentária contidos em estudos socioeconômicos dos municípios selecionados, divulgados anualmente pela Secretaria Geral de Planejamento do Tribunal de Contas do Estado do Rio de Janeiro. A pesquisa foi realizada com dados dos orçamentos públicos no período de 2000 a 2011, por ser o ano mais recente com dados publicados, até a data de elaboração do presente texto. Os indicadores elaborados são:

i. Comprometimento da receita corrente com a máquina administrativa (despesas de custeio/receitas correntes). Esse indicador mede o nível de comprometimento dos municípios com a máquina administrativa, quando utiliza recursos oriundos de receitas correntes. São despesas necessárias à manutenção de serviços, pagamentos de pessoal e manutenção de prédios públicos;

ii. Grau de investimento (investimentos/receita total). Reflete a contribuição da receita total na execução dos investimentos, ou seja, quanto da receita foi despendido para fins de investimento em obras públicas e infraestrutura, por exemplo;

iii. Dependência de recursos de royalties e participações especiais (royalties e PE/receita realizada). O objetivo é demonstrar o percentual de participação das compensações financeiras na receita efetivamente realizada desses municípios;

iv. Autonomia financeira (receita tributária própria/despesas de custeio). Mede a contribuição da receita própria dos municípios, não incluídas as parcelas de royalties, participações especiais e demais transferências, no atendimento às despesas com o custeio;

v. Esforço tributário próprio (receita tributária própria, mais a inscrição líquida na dívida ativa/receita arrecadada). O objetivo é comparar o esforço tributário próprio que os municípios realizam no sentido de arrecadar os seus próprios tributos, em relação a todas as receitas arrecadadas.

Trata-se, portanto, de um conjunto de indicadores financeiros que possibilitará a avaliação da evolução fiscal dos municípios selecionados durante doze anos, período este coincidente com o início dos recebimentos das participações governamentais até o ano de 2011. Nesse contexto, os dados serão relevantes para mostrar qual o peso das receitas petrolíferas nos orçamentos e como uma possível dependência influencia a autonomia financeira ou mesmo o esforço tributário próprio. 


\section{Os orçamentos e seus indicadores}

\subsection{Campos dos Goytacazes}

O Município de Campos dos Goytacazes, de acordo com os dados apresentados abaixo, conseguiu nos anos de 2010 e 2011 estabilizar o comprometimento de suas receitas com despesas de custeio, ainda que em patamar elevado (75\%). A dependência orçamentária das participações governamentais também permanece estabilizada em 59\% das receitas no mesmo período. As informações importantes e positivas na tabela abaixo demonstram que tanto o grau de investimento como a autonomia financeira e o esforço tributário próprio subiram nos anos de 2010 e 2011. Em comparação com o Município de Belford Roxo, observa-se que a cidade da Baixada Fluminense mantém um padrão de comportamento orçamentário quase linear durante todo o período pesquisado: indicador de custeio elevado, pequeno investimento, baixa autonomia financeira e moderado esforço tributário. Como não há influência de receitas petrolíferas, os indicadores orçamentários permanecem estáveis.

Tabela 2

Indicadores orçamentários 2000-2011.

Município de Campos dos Goytacazes (RJ)

\begin{tabular}{|c|c|c|c|c|c|}
\hline Ano & Custeio ${ }^{(1)}$ & $\begin{array}{l}\text { Grau de Investimento } \\
\text { (2) }\end{array}$ & $\begin{array}{l}\text { Royalties } \\
\text { e PE }{ }^{(3)}\end{array}$ & $\begin{array}{l}\text { Autonomia Financeira } \\
\text { (4) }\end{array}$ & $\begin{array}{c}\text { Esforço } \\
\text { Tributário Próprio (5) }\end{array}$ \\
\hline 2000 & $42 \%$ & $33 \%$ & $55,20 \%$ & $15,40 \%$ & $12 \%$ \\
\hline 2001 & $42 \%$ & $25 \%$ & $54,30 \%$ & $13,60 \%$ & $8,10 \%$ \\
\hline 2002 & $50 \%$ & $22 \%$ & $57 \%$ & $7,50 \%$ & $4,80 \%$ \\
\hline 2003 & $76 \%$ & $18 \%$ & $66 \%$ & $4,90 \%$ & $4,90 \%$ \\
\hline 2004 & $91 \%$ & $14,8 \%$ & $69 \%$ & $4,50 \%$ & $4,20 \%$ \\
\hline 2005 & $83 \%$ & $10 \%$ & $72 \%$ & $5,60 \%$ & $6,80 \%$ \\
\hline 2006 & $80 \%$ & $13,2 \%$ & $73 \%$ & $7,20 \%$ & $5,90 \%$ \\
\hline 2007 & $86 \%$ & $21,6 \%$ & $63 \%$ & $7,00 \%$ & $6 \%$ \\
\hline 2008 & $70 \%$ & $18 \%$ & $71 \%$ & $7,20 \%$ & $5 \%$ \\
\hline 2009 & $74 \%$ & $11 \%$ & $62 \%$ & $6,40 \%$ & $6,20 \%$ \\
\hline 2010 & $75 \%$ & $24,9 \%$ & $59 \%$ & $9,5 \%$ & $7,1 \%$ \\
\hline 2011 & $75 \%$ & $20,4 \%$ & $59 \%$ & $10,6 \%$ & $7,9 \%$ \\
\hline
\end{tabular}

Fonte: Tabulação dos autores com base em dados do TCE-RJ. Perfil dos Municípios do Estado. www.tce.rj.gov.br

Percentual de comprometimento da receita corrente com a máquina administrativa

(1) Percentual da receita total gasto com investimentos

(2) Dependência das compensações financeiras

(3) Contribuição da receita tributária própria no atendimento às despesas de custeio, exceto royalties, PE e demais transferências

(4) Mede a capacidade de arrecadar seus próprios tributos em relação às demais receitas arrecadadas

Figura 1

Evolução dos indicadores orçamentários em Campos dos Goytacazes (2000-2011)

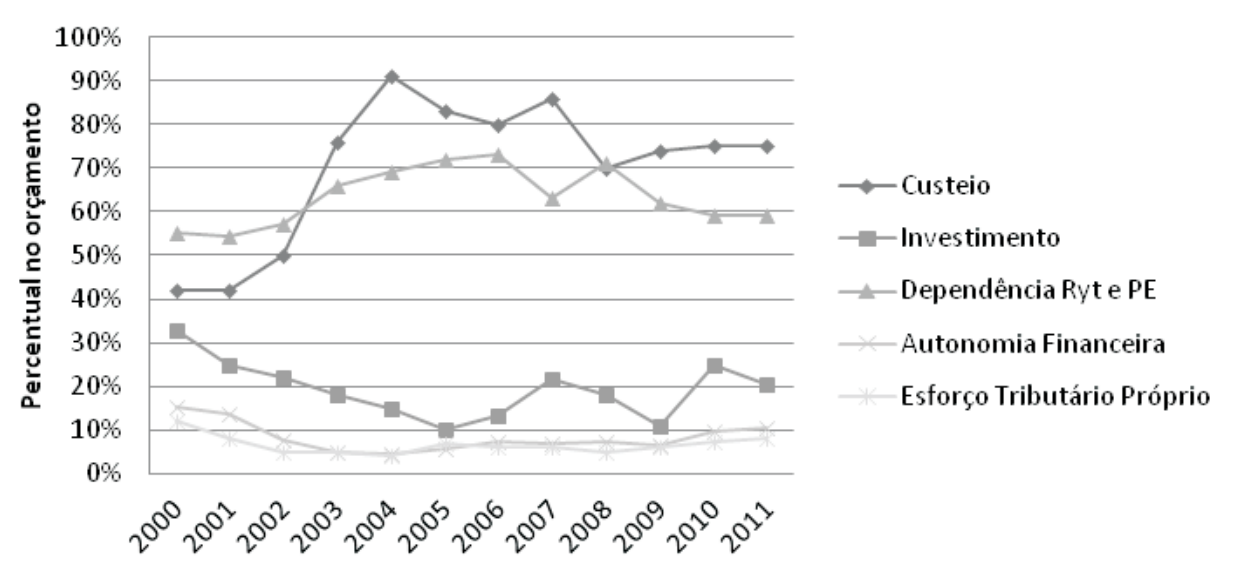


Tabela 3

Indicadores Orçamentários 2000-2011. Município de Belford Roxo (RJ)

\begin{tabular}{|c|c|c|c|c|c|}
\hline Ano & Custeio (1) & Grau de Investimento (2) & Royalties e PE (3) & $\begin{array}{l}\text { Autonomia Financeira } \\
\text { (4) }\end{array}$ & $\begin{array}{l}\text { Esforço Tributário } \\
\text { Próprio (5) }\end{array}$ \\
\hline 2000 & $78 \%$ & $6 \%$ & $0 \%$ & $17,30 \%$ & $12 \%$ \\
\hline 2001 & $85 \%$ & $6 \%$ & $1 \%$ & $12,10 \%$ & $10,30 \%$ \\
\hline 2002 & $98 \%$ & $10 \%$ & $1 \%$ & $13,10 \%$ & $12,90 \%$ \\
\hline 2003 & $100 \%$ & $5 \%$ & $2 \%$ & $9,30 \%$ & $9,30 \%$ \\
\hline 2004 & $93 \%$ & $4,59 \%$ & $4 \%$ & $8,60 \%$ & $9,20 \%$ \\
\hline 2005 & $87 \%$ & $5 \%$ & $6 \%$ & $15,00 \%$ & $2,90 \%$ \\
\hline 2006 & $89 \%$ & $10,97 \%$ & $4 \%$ & $10,60 \%$ & $21,10 \%$ \\
\hline 2007 & $89 \%$ & $2,32 \%$ & $4 \%$ & $11,00 \%$ & $2 \%$ \\
\hline 2008 & $92 \%$ & $5 \%$ & $4 \%$ & $10,10 \%$ & $12 \%$ \\
\hline 2009 & $95 \%$ & $3 \%$ & $3 \%$ & $11,10 \%$ & $29,70 \%$ \\
\hline 2010 & $91 \%$ & $8,95 \%$ & $3 \%$ & $12,60 \%$ & $23,20 \%$ \\
\hline 2011 & $96 \%$ & $8,55 \%$ & $3 \%$ & $11,6 \%$ & $16,5 \%$ \\
\hline
\end{tabular}

Fonte: Tabulação dos autores com base em dados do TCE-RJ. Perfil dos Municípios do Estado. www.tce.ri.gov.br.

(1) Percentual de comprometimento da receita corrente com a máquina administrativa

(2) Percentual da receita total gasto com investimentos

(3) Dependência das compensações financeiras

(4) Contribuição da receita tributária própria no atendimento às despesas de custeio, exceto royalties, PE e demais transferências

(5) Mede a capacidade de arrecadar seus próprios tributos em relação às demais receitas arrecadadas

Figura 2

Evolução dos indicadores orçamentários em Belford Roxo (2000-2011)

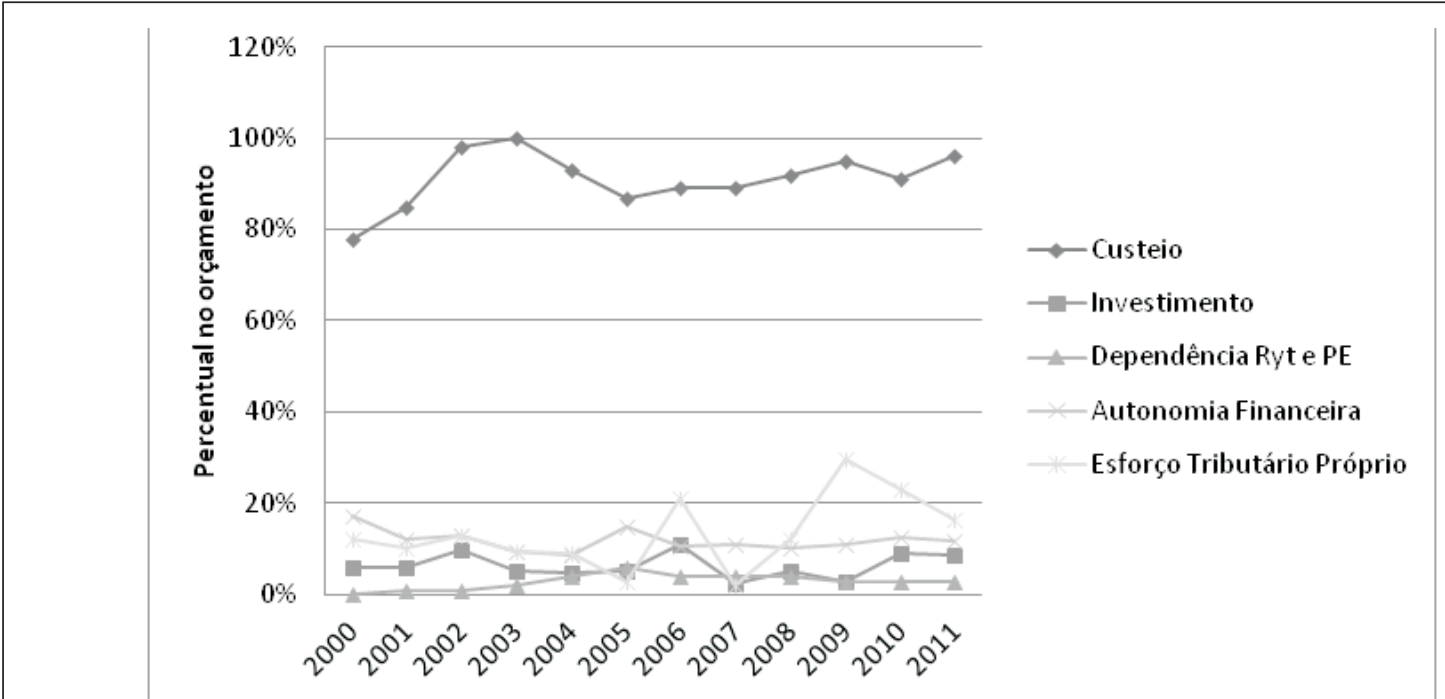

Fonte: Perfil dos municípios do estado. www.tce.ri.gov.br

\subsection{Macaé}

O Município de Macaé se destaca pela sua menor dependência dos royalties e participações especiais comparando-se aos demais municípios do norte fluminense selecionados. No ano de 2011, o percentual das receitas orçamentárias formado por essas participações alcançou o ótimo patamar de 31\%. A cidade de Macaé vem abrigando inúmeras empresas voltadas para a atividade petrolífera que movimentam a economia local, possibilitando uma arrecadação maior de tributos municipais. Pode-se confirmar esta informação observando-se no gráfico abaixo o aumento nos indicadores de autonomia financeira e de esforço tributário próprio. Os percentuais de grau de comprometimento com custeio (73\%) e grau de investimentos (11\% e 9\%) permaneceram estáveis nos anos de 2010 e 2011. Comparando-se os dados de Macaé com os da cidade de Volta Redonda, percebe-se que o município situado na região sul fluminense não sofre influência relevante das rendas petrolíferas e, portanto, mantém um padrão estável de comportamento orçamentário durante todo o período, caracterizado por elevado custeio e bons percentuais de autonomia financeira e esforço tributário próprio. 
Tabela 4

Indicadores orçamentários 2000-2011. Município de Macaé (RJ)

\begin{tabular}{|c|c|c|c|c|c|}
\hline Ano & Custeio (1) & Grau de Investimento (2) & Royalties e PE (3) & $\begin{array}{l}\text { Autonomita Financelira } \\
\text { (4) }\end{array}$ & $\begin{array}{l}\text { Esforço Tांगutitíto } \\
\text { Prónrio (5) }\end{array}$ \\
\hline 2000 & $62 \%$ & $18 \%$ & $53 \%$ & $16 \%$ & $14 \%$ \\
\hline 2001 & $60 \%$ & $14 \%$ & $50 \%$ & $19 \%$ & $13 \%$ \\
\hline 2002 & $58 \%$ & $11 \%$ & $54 \%$ & $21 \%$ & $16 \%$ \\
\hline 2003 & $67 \%$ & $28,7 \%$ & $52 \%$ & $18 \%$ & $14 \%$ \\
\hline 2004 & $68 \%$ & $37,1 \%$ & $55 \%$ & $25 \%$ & $19 \%$ \\
\hline 2005 & $80 \%$ & $16,9 \%$ & $57 \%$ & $22,3 \%$ & $19,6 \%$ \\
\hline 2006 & $94 \%$ & $6,8 \%$ & $57 \%$ & $20,4 \%$ & $20 \%$ \\
\hline 2007 & $83 \%$ & $8,1 \%$ & $40 \%$ & $25,6 \%$ & $21,9 \%$ \\
\hline 2008 & $78 \%$ & $8 \%$ & $45 \%$ & $27,9 \%$ & $22,1 \%$ \\
\hline 2009 & $77 \%$ & $16 \%$ & $33 \%$ & $36,7 \%$ & $29,6 \%$ \\
\hline 2010 & $73 \%$ & $11,45 \%$ & $34 \%$ & $35,6 \%$ & $27 \%$ \\
\hline 2011 & $73 \%$ & $9,64 \%$ & $31 \%$ & $37,1 \%$ & $28,5 \%$ \\
\hline
\end{tabular}

Fonte: Tabulação dos autores com base em dados do TCE-RJ. Perfil dos Municípios do Estado. www.tce.rj.gov.br

(1) Percentual de comprometimento da receita corrente com a máquina administrativa

(2) Percentual da receita total gasto com investimentos

(3) Dependência às compensações financeiras

(4) Contribuição da receita tributária própria no atendimento às despesas de custeio, exceto royalties, PE e demais transferências

(5) Mede a capacidade de arrecadar seus próprios tributos em relação às demais receitas arrecadadas

Figura 3

Evolução dos indicadores orçamentários em Macaé (2000-2011)

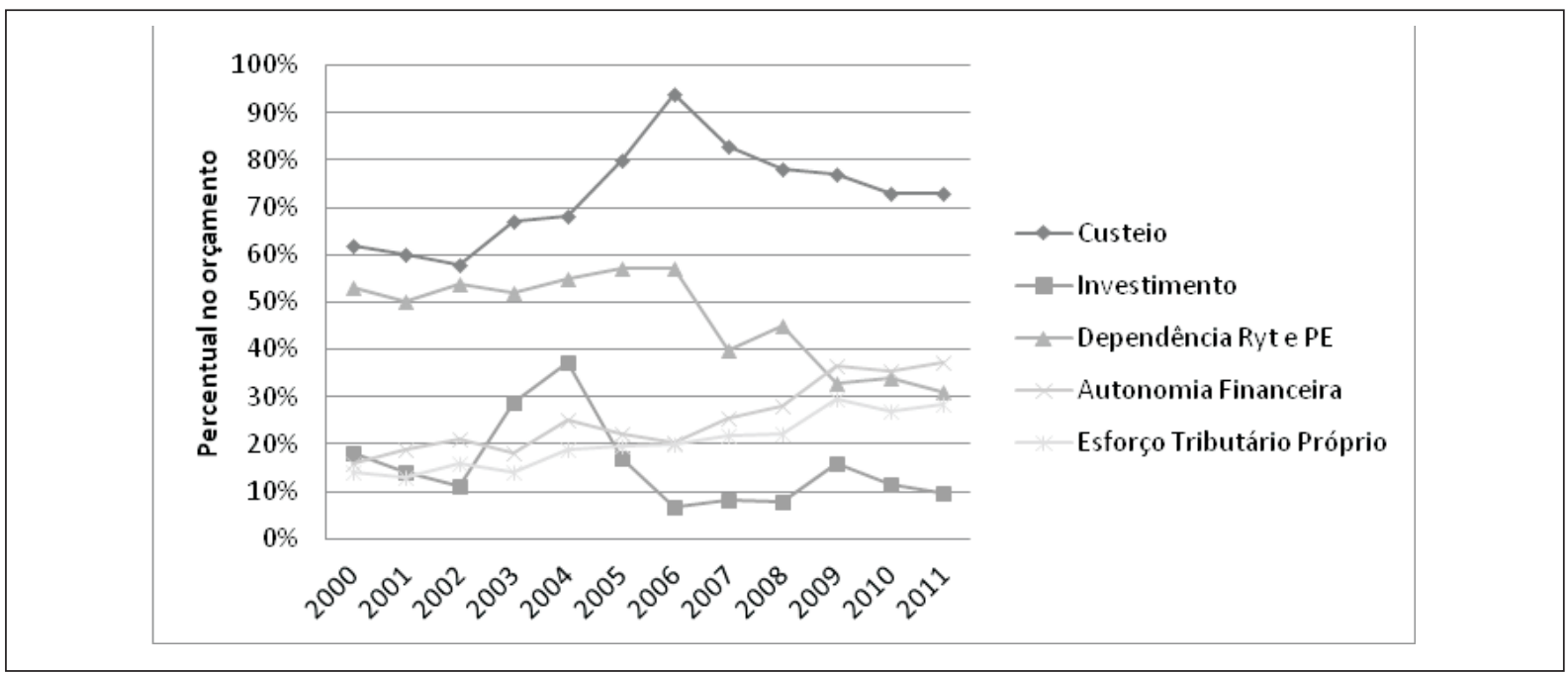

Fonte: Perfil dos municípios do estado. www.tce.rj.gov.br

Tabela 5

Indicadores orçamentários 2000-2011. Município de Volta Redonda (RJ)

\begin{tabular}{|c|c|c|c|c|c|}
\hline Ano & Custeio (1) & $\begin{array}{l}\text { Grau de Investimento } \\
\text { (2) }\end{array}$ & Royalties e PE (3) & $\begin{array}{l}\text { Autonomia Financeira } \\
\text { (4) }\end{array}$ & $\begin{array}{l}\text { Esforço Tributário } \\
\text { Próprio (5) }\end{array}$ \\
\hline 2000 & $43 \%$ & $6 \%$ & $0 \%$ & $44 \%$ & $25 \%$ \\
\hline 2001 & $45 \%$ & $10 \%$ & $0 \%$ & $47 \%$ & $27 \%$ \\
\hline 2002 & $98 \%$ & $10 \%$ & $0 \%$ & $22 \%$ & $30 \%$ \\
\hline 2003 & $99 \%$ & $12,67 \%$ & $0 \%$ & $23 \%$ & $30 \%$ \\
\hline 2004 & $89 \%$ & $6,27 \%$ & $4 \%$ & $26 \%$ & $27 \%$ \\
\hline 2005 & $92 \%$ & $5,72 \%$ & $5 \%$ & $25,8 \%$ & $33,4 \%$ \\
\hline 2006 & $97 \%$ & $5,18 \%$ & $5 \%$ & $20,9 \%$ & $27 \%$ \\
\hline 2007 & $69 \%$ & $7,97 \%$ & $0 \%$ & $28,4 \%$ & $32,5 \%$ \\
\hline 2008 & $80 \%$ & $14 \%$ & $0 \%$ & $27,2 \%$ & $25,3 \%$ \\
\hline
\end{tabular}




\begin{tabular}{r|r|r|r|r|r|}
\hline $\mathbf{2 0 0 9}$ & $93 \%$ & $15 \%$ & $0 \%$ & $19,7 \%$ & $22, \%$ \\
\hline $\mathbf{2 0 1 0}$ & $89 \%$ & $16,36 \%$ & $5 \%$ & $20 \%$ & $24,4 \%$ \\
\hline $\mathbf{2 0 1 1}$ & $94 \%$ & $21,62 \%$ & $4 \%$ & $19,6 \%$ & $23,8 \%$ \\
\hline
\end{tabular}

Fonte: Tabulação dos autores com base em dados do TCE-RJ. Perfil dos Municípios do Estado. www.tce.rj.gov.br.

(1) Percentual de comprometimento da receita corrente com a máquina administrativa

(2) Percentual da receita total gasto com investimentos

(3) Dependência às compensações financeiras

(4) Contribuição da receita tributária própria no atendimento às despesas de custeio, exceto royalties, PE e demais transferências

(5) Mede a capacidade de arrecadar seus próprios tributos em relação às demais receitas arrecadadas

Figura 4

Evolução dos indicadores orçamentários em Volta Redonda (2000-2011)

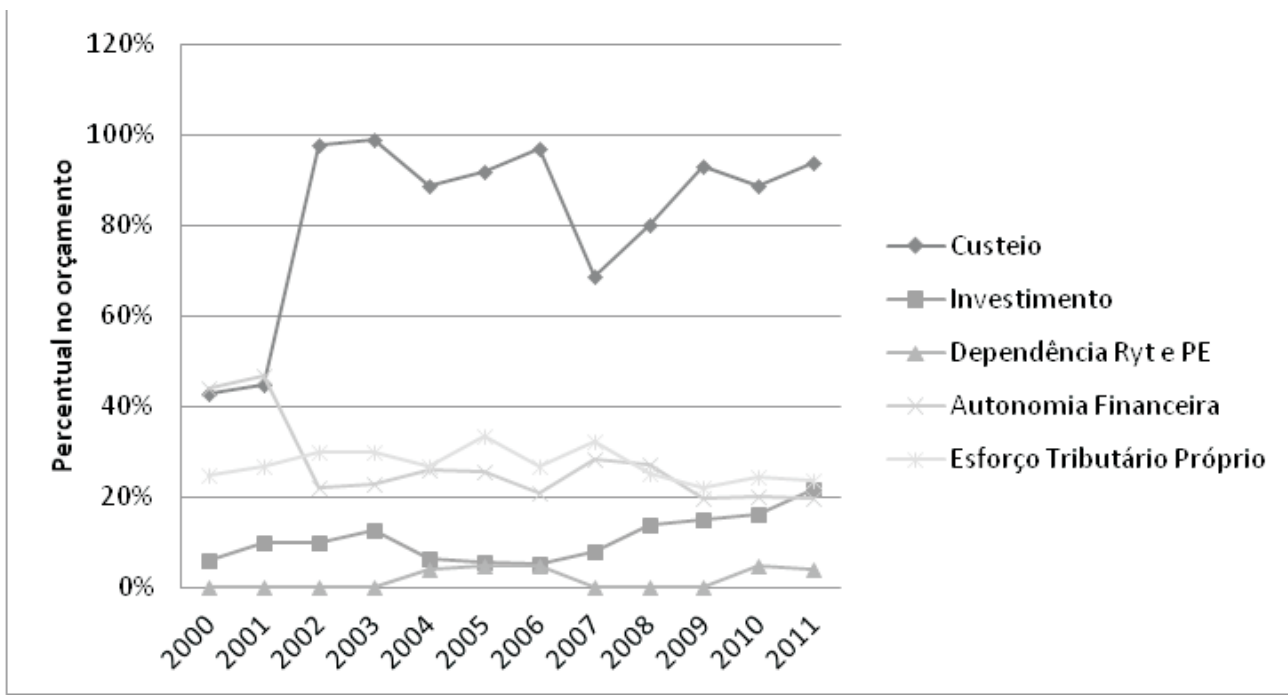

Fonte: Perfil dos municípios do estado. www.tce.ri.gov.br

\subsection{Rio das Ostras}

Os dados observados na Tabela 6 são positivos para o Município de Rio das Ostras nos anos de 2010 e 2011. O comprometimento do orçamento com as despesas de custeio caiu para 64\% em 2010 e se manteve estabilizado em 2011. O grau de investimento em torno de $20 \%$ no mesmo período e as elevações dos indicadores de autonomia financeira e esforço tributário são favoráveis. Merece maior destaque ainda a queda na dependência das participações governamentais para o percentual de 52\% em 2011. No Município de Resende, a exemplo de Belford Roxo e Volta Redonda, as rendas petrolíferas também não são significativas para o seu orçamento, razão pela qual a evolução dos indicadores orçamentários é estável. Apesar do acentuado grau de comprometimento das receitas com despesas de custeio, a cidade de Resende possui melhores índices nos quesitos autonomia financeira e esforço tributário próprio frente ao Município de Rio das Ostras.

Tabela 6.

Indicadores orçamentários 2000-2011. Município de Rio das 0stras (RJ)

\begin{tabular}{|c|c|c|c|c|c|}
\hline Ano & Custeio (1) & $\begin{array}{l}\text { Grau de Investimento } \\
\text { (2) }\end{array}$ & Royalties e PE (3) & $\begin{array}{l}\text { Autonomia Financeira } \\
\text { (4) }\end{array}$ & $\begin{array}{l}\text { Esforço Tributário } \\
\text { Próprio (5) }\end{array}$ \\
\hline 2000 & $45 \%$ & $23,40 \%$ & $73 \%$ & $10 \%$ & $11 \%$ \\
\hline 2001 & $35 \%$ & $28 \%$ & $74 \%$ & $11 \%$ & $4 \%$ \\
\hline 2002 & $39 \%$ & $40 \%$ & $76 \%$ & $8 \%$ & $3,60 \%$ \\
\hline 2003 & $46 \%$ & $40,80 \%$ & $64 \%$ & $8,50 \%$ & $4,30 \%$ \\
\hline 2004 & $51 \%$ & $62,10 \%$ & $66 \%$ & $13 \%$ & $9,40 \%$ \\
\hline 2005 & $53 \%$ & $42,40 \%$ & $74 \%$ & $10,60 \%$ & $7,10 \%$ \\
\hline 2006 & $89 \%$ & $57,40 \%$ & $73 \%$ & $11,30 \%$ & $7,60 \%$ \\
\hline 2007 & $89 \%$ & $26,60 \%$ & $65 \%$ & $10,80 \%$ & $14,20 \%$ \\
\hline
\end{tabular}




\begin{tabular}{r|r|r|r|r|r}
\hline $\mathbf{2 0 0 8}$ & $\mathbf{7 0}$ & $17 \%$ & $68 \%$ & $13,90 \%$ & $15,60 \%$ \\
\hline $\mathbf{2 0 0 9}$ & $85 \%$ & $12 \%$ & $59 \%$ & $12,60 \%$ & $14 \%$ \\
\hline $\mathbf{2 0 1 0}$ & $64 \%$ & $20,76 \%$ & $59 \%$ & $14,1 \%$ & $12,2 \%$ \\
\hline $\mathbf{2 0 1 1}$ & $65 \%$ & $19,67 \%$ & $52 \%$ & $15,8 \%$ & \\
\hline
\end{tabular}

Fonte: Tabulação dos autores com base em dados do TCE-RJ. Perfil dos Municípios do Estado. www.tce.rj.gov.br

(1) Percentual de comprometimento da receita corrente com a máquina administrativa

(2) Percentual da receita total gasto com investimentos

(3) Dependência às compensações financeiras

(4) Contribuição da receita tributária própria no atendimento às despesas de custeio, exceto royalties, PE e demais transferências

(5) Mede a capacidade de arrecadar seus próprios tributos em relação às demais receitas arrecadadas

Figura 5

Evolução dos indicadores orçamentários em Rio das Ostras (2000-2011)

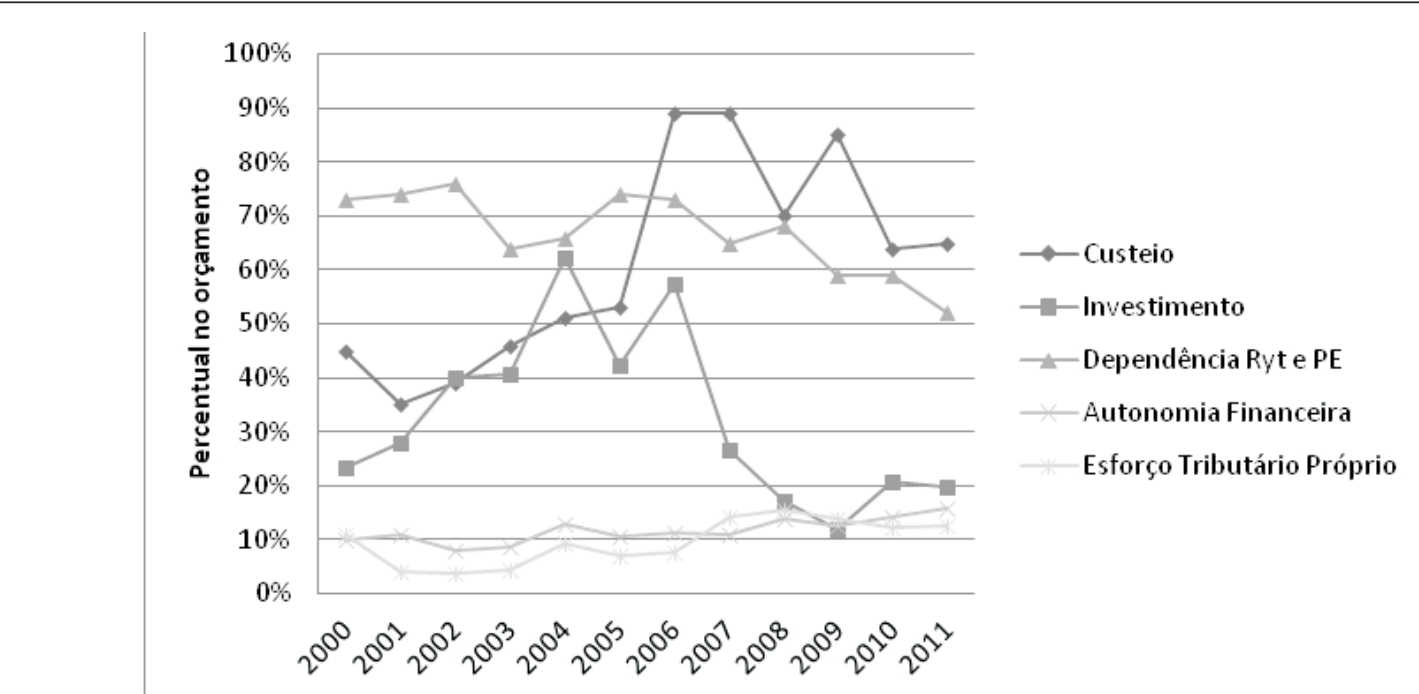

Fonte: Perfil dos municípios do estado. www.tce.rj.gov.br

Tabela 7.

Indicadores orçamentários 2000-2011. Município de Resende (RJ)

\begin{tabular}{|c|c|c|c|c|c|}
\hline Ano & Custeio (1) & Grau de Investimento (2) & Royalties e PE (3) & Autonomia Financeira (4) & Esforço Tributário Próprio (5) \\
\hline 2000 & $82 \%$ & $8,50 \%$ & $1 \%$ & $14 \%$ & $21 \%$ \\
\hline 2001 & $78 \%$ & $7 \%$ & $2 \%$ & $15 \%$ & $16 \%$ \\
\hline 2002 & $78 \%$ & $8 \%$ & $2 \%$ & $15 \%$ & $10,00 \%$ \\
\hline 2003 & $93 \%$ & $4,47 \%$ & $2 \%$ & $13,20 \%$ & $15,00 \%$ \\
\hline 2004 & $89 \%$ & $6,84 \%$ & $3 \%$ & $16 \%$ & $15,70 \%$ \\
\hline 2005 & $80 \%$ & $3,88 \%$ & $3 \%$ & $21,80 \%$ & $21,20 \%$ \\
\hline 2006 & $88 \%$ & $16,12 \%$ & $2 \%$ & $17,10 \%$ & $16,70 \%$ \\
\hline 2007 & $86 \%$ & $5,85 \%$ & $5 \%$ & $18,00 \%$ & $17,30 \%$ \\
\hline 2008 & $83 \%$ & $14 \%$ & $6 \%$ & $19,70 \%$ & $17,60 \%$ \\
\hline 2009 & $86 \%$ & $5 \%$ & $5 \%$ & $21,70 \%$ & $23 \%$ \\
\hline 2010 & $84 \%$ & $6,16 \%$ & $6 \%$ & $19,5 \%$ & $18,8 \%$ \\
\hline 2011 & $86 \%$ & $9,1 \%$ & $6 \%$ & $20,1 \%$ & $18,7 \%$ \\
\hline
\end{tabular}

Fonte: Tabulação dos autores com base em dados do TCE-RJ. Perfil dos Municípios do Estado. www.tce.ri.gov.br.

(1) Percentual de comprometimento da receita corrente com a máquina administrativa

(2) Percentual da receita total gasto com investimentos

(3) Dependência às compensações financeiras

(4) Contribuição da receita tributária própria no atendimento às despesas de custeio, exceto royalties, PE e demais transferências

(5) Mede a capacidade de arrecadar seus próprios tributos em relação às demais receitas arrecadadas 
Figura 6

Evolução dos indicadores orçamentários em Resende

(2000-2011)

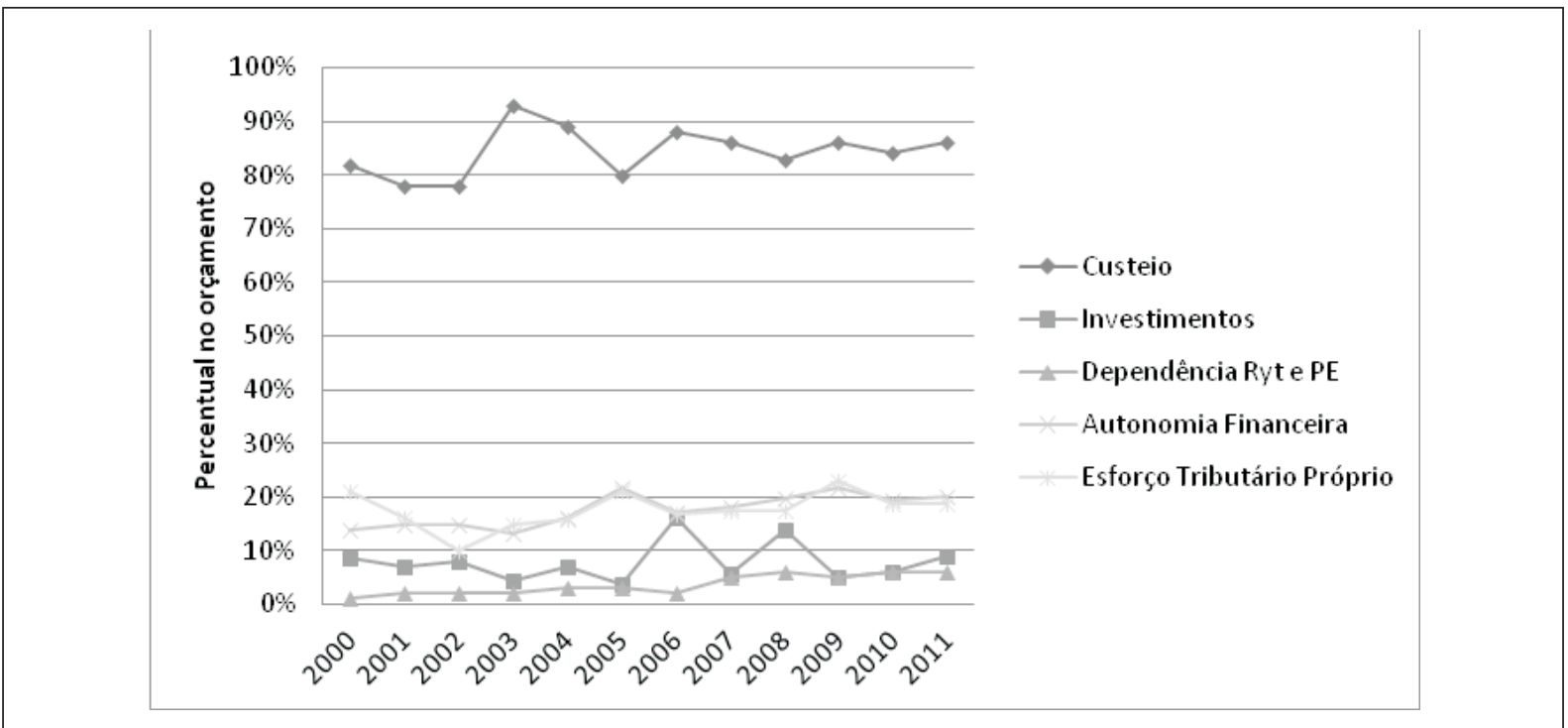

Fonte: Perfil dos municípios do estado. www.tce.ri.gov.br

\subsection{São João da Barra}

No caso do Município de São João da Barra, em que pese a ligeira redução do comprometimento de suas receitas com custeio, 74\% e 69\% em 2010 e 2011 respectivamente, as informações apresentadas na Tabela 8 não são favoráveis. O grau de investimento diminuiu da ordem de 52\% em 2009 para 10\% em 2011, os indicadores de autonomia financeira e esforço tributário próprio mantiveram-se em patamares baixos, ao passo que a dependência das participações petrolíferas continua alta, 75\% e 74\% em 2010 e 2011 respectivamente. Há um desequilíbrio evidente nos indicadores orçamentários de São João da Barra, ao contrário do Município de Piraí, cuja evolução dos indicadores mantém um padrão equilibrado de comportamento, associado a dados de crescimento no grau de investimento.

Tabela 8

Indicadores orçamentários 2000-2011. Município de São João da Barra (RJ)

\begin{tabular}{|c|c|c|c|c|c|}
\hline Ano & Custeio (1) & $\begin{array}{r}\text { Grau de Investimento } \\
\text { (2) }\end{array}$ & Royalties e PE (3) & $\begin{array}{r}\text { Autonomia Financeira } \\
\text { (4) }\end{array}$ & $\begin{array}{r}\text { Esforço Tributário } \\
\text { Próprio (5) }\end{array}$ \\
\hline 2000 & $67 \%$ & $30,80 \%$ & $44 \%$ & $4,60 \%$ & $6,50 \%$ \\
\hline 2001 & $58 \%$ & $20 \%$ & $42 \%$ & $5,80 \%$ & $6,30 \%$ \\
\hline 2002 & $99 \%$ & $13 \%$ & $19 \%$ & $3,80 \%$ & $8,30 \%$ \\
\hline 2003 & $71 \%$ & $17,90 \%$ & $55 \%$ & $3,60 \%$ & $4,60 \%$ \\
\hline 2004 & $93 \%$ & $12,10 \%$ & $59 \%$ & $3 \%$ & $5,70 \%$ \\
\hline 2005 & $90 \%$ & $6,50 \%$ & $64 \%$ & $3 \%$ & $5,50 \%$ \\
\hline 2006 & $95 \%$ & $4,90 \%$ & $67 \%$ & $2,70 \%$ & $5,30 \%$ \\
\hline 2007 & $109 \%$ & $9,70 \%$ & $52 \%$ & $3,20 \%$ & $5,70 \%$ \\
\hline 2008 & $67 \%$ & $19 \%$ & $75 \%$ & $7,60 \%$ & $5,70 \%$ \\
\hline 2009 & $78 \%$ & $52 \%$ & $74 \%$ & $6,20 \%$ & $5,70 \%$ \\
\hline 2010 & $74 \%$ & $24,62 \%$ & $75 \%$ & $5,8 \%$ & $5,0 \%$ \\
\hline 2011 & $69 \%$ & $10,08 \%$ & $73 \%$ & $8,4 \%$ & $6,4 \%$ \\
\hline
\end{tabular}

Fonte: Tabulação dos autores com base em dados do TCE-RJ. Perfil dos Municípios do Estado. www.tce.ri.gov.br.

(1) Percentual de comprometimento da receita corrente com a máquina administrativa

(2) Percentual da receita total gasto com investimentos

(3) Dependência às compensações financeiras

(4) Contribuição da receita tributária própria no atendimento às despesas de custeio, exceto royalties, PE e demais transferências

(5) Mede a capacidade de arrecadar seus próprios tributos em relação às demais receitas arrecadadas 
Figura 7

Evolução dos indicadores orçamentários em São João da Barra (2000-2009)

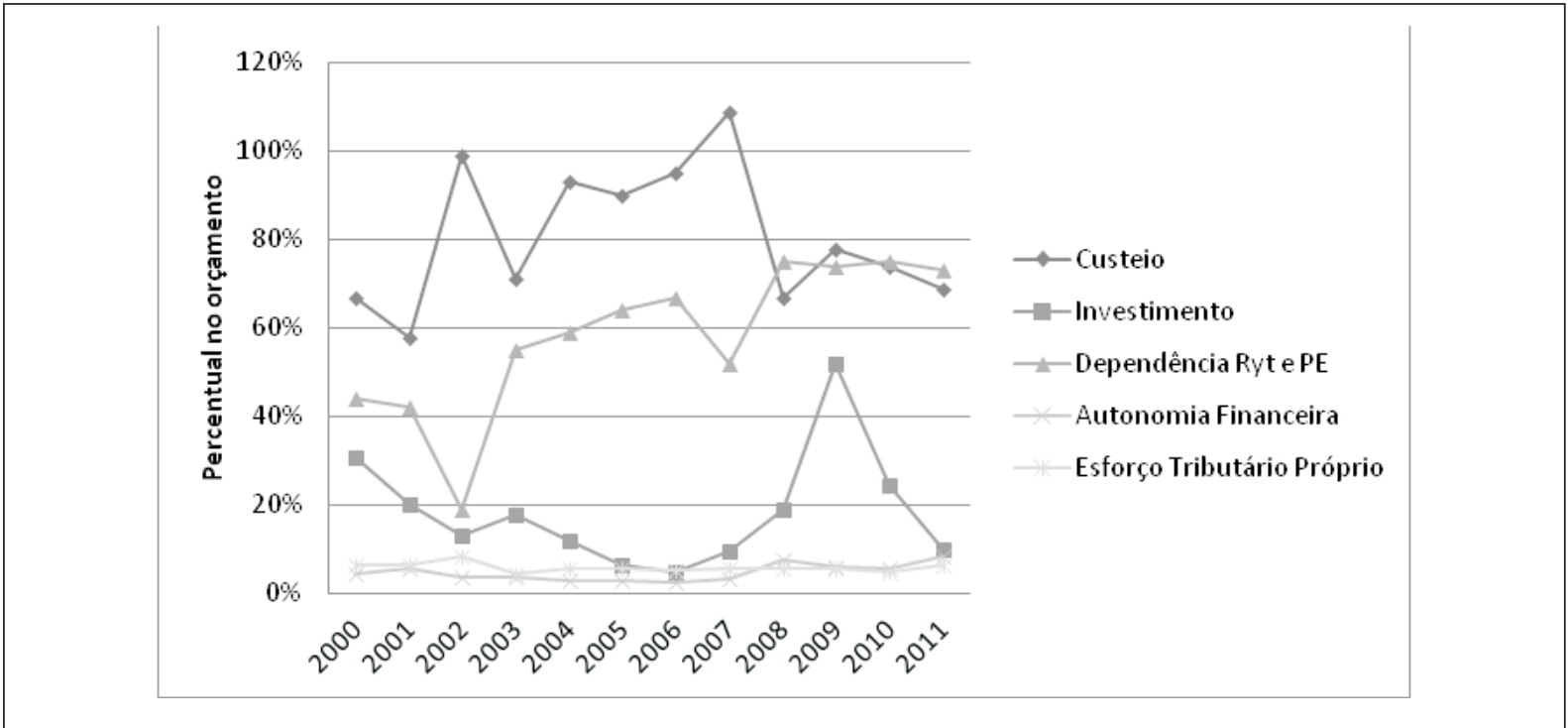

Fonte: Perfil dos municípios do estado. www.tce.rj.gov.br

\section{Tabela 9}

Indicadores orçamentários 2000-2011. Município de Piraí (RJ)

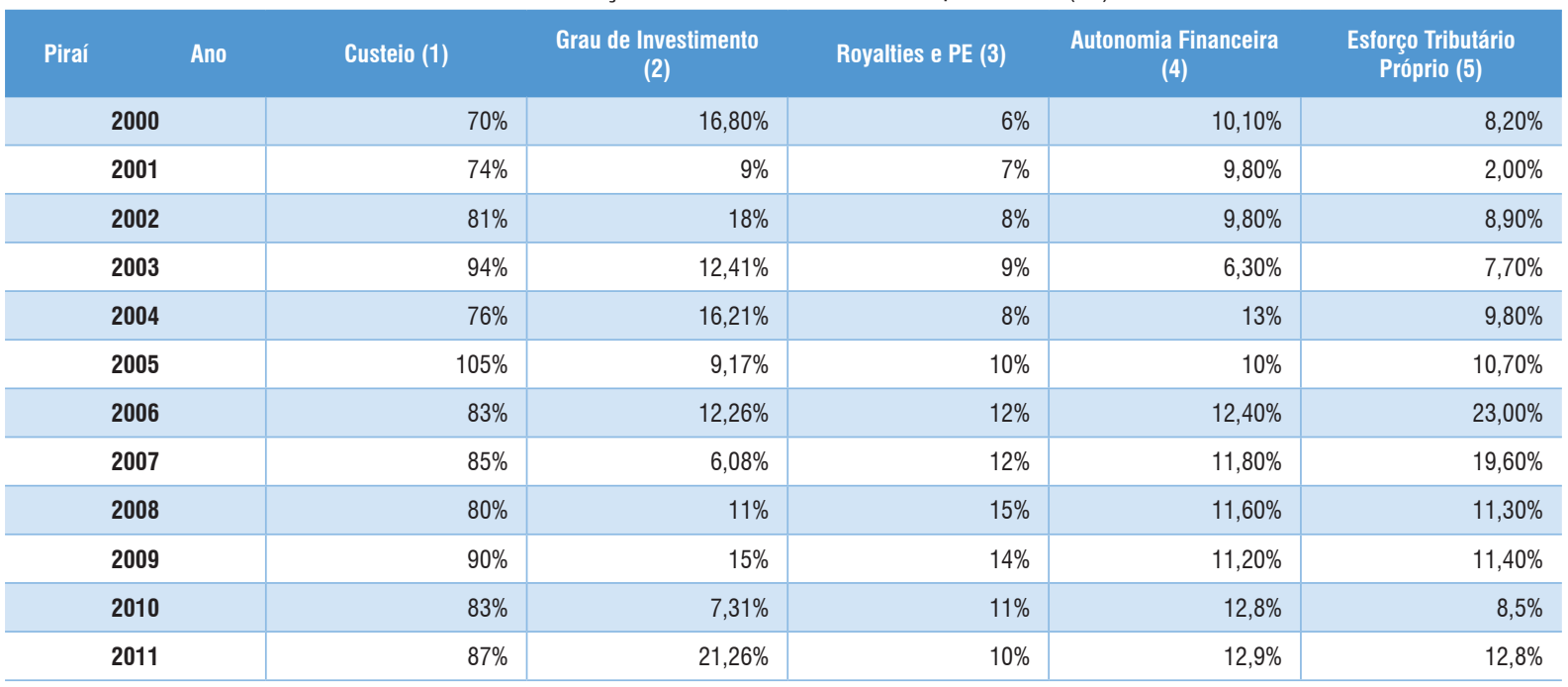

Fonte: Tabulacão doa autores com base em dados do TCE-RJ. Perfil dos Municípios do Estado. www.tce.ri.gov.br.

(1) Percentual de comprometimento da receita corrente com a máquina administrativa

(2) Percentual da receita total gasto com investimentos

(3) Dependência às compensaçôes financeiras

(4) Contribuição da receita tributária própria no atendimento às despesas de custeio, exceto royalties, PE e demais transferências

(5) Mede a capacidade de arrecadar seus próprios tributos em relação às demais receitas arrecadadas 
Figura 8

Evolução dos indicadores orçamentários em Piraí (2000-2011)

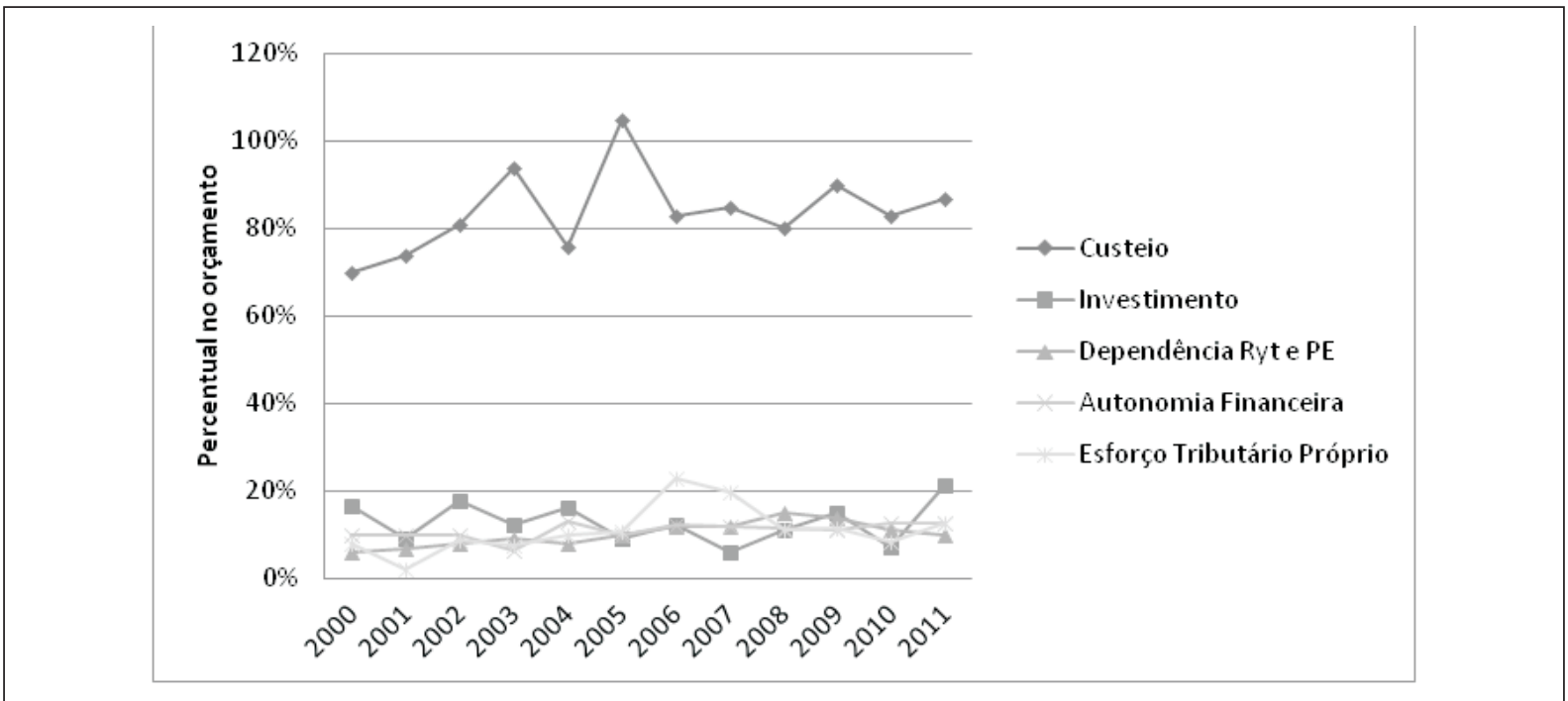

Fonte: Perfil dos municípios do estado. www.tce.rj.gov.br

\section{Os efeitos das rendas petrolíferas nos orçamentos municipais}

O debate sobre a influência dos royalties e participações especiais nos orçamentos dos municípios ditos "produtores", também convencionados petro-rentistas (Serra, Terra e Pontes, 2006), não é de agora. Além das comprovadas mudanças estruturais na população, emprego, território, quadro político e cultura, promovidas pela indústria do petróleo nas localidades afetadas pela produção e extração deste recurso natural (Piquet e Terra, 2011:39), as participações governamentais oriundas dessa atividade econômica vêm exercendo significativa influência nos orçamentos fiscais desses municípios. A observação cuidadosa das informações apresentadas nas tabelas e gráficos deste artigo remete a um padrão similar de comportamento dos indicadores orçamentários nos municípios pesquisados, com pontuais exceções. Trata-se do ciclo da dependência.

Nesta série de fenômenos econômicos e financeiros que se apresentam nos orçamentos, podem ser indicadas as seguintes fases:

i. Inicialmente ocorre um boom de rendas petrolíferas que estimulam as administrações municipais a realizarem grandes investimentos, na maioria das vezes em capital físico, ou seja, construção de escolas, postos de saúde, equipamentos de lazer, estradas e outros. Por outro lado, os recursos financeiros em caixa desestimulam o esforço arrecadatório dessas cidades, reduzindo indicadores como autonomia financeira e esforço tributário próprio.

ii. Em um segundo momento, as receitas petrolíferas passam a ser consumidas pela manutenção dos investimentos realizados e, por conseguinte, reduz-se o grau de investimento e eleva-se o grau de comprometimento das receitas com despesas de custeio. A dependência orçamentária às rendas petrolíferas mantém-se em patamares altos.

iii. Em um terceiro momento, tende a ocorrer um equilíbrio orçamentário, fundamentado na redução dos graus de comprometimento com o custeio e de dependência. Também é possível observar um aumento no percentual de investimento e melhora nos indicadores de autonomia financeira e esforço tributário próprio. 


\section{Considerações finais}

Este artigo trabalhou com a atualização de indicadores orçamentários de municípios selecionados do norte fluminense nos anos de 2010 e 2011. À exceção do município de São João da Barra, os municípios de Campos dos Goytacazes, Macaé e Rio das Ostras apresentaram dados positivos e substanciais melhoras em alguns indicadores como a redução da dependência orçamentária, do comprometimento das receitas com custeio e aumento do grau de investimentos, da autonomia financeira e do esforço tributário próprio. Alguns fatores podem explicar esta mudança de paradigma no comportamento dos orçamentos.

O primeiro deles é o conservadorismo na administração das despesas públicas municipais imposto pelo temor de perda substancial das rendas petrolíferas, por conta da ameaça de alteração dos critérios legais para a redistribuição dessas rendas, conforme amplamente noticiado pelos veículos de comunicação e pelas manifestações públicas contra e a favor emitidas pelos diversos segmentos da sociedade nos anos de 2010, 2011 e 2012. E não é para menos, pois, até o presente momento no ano de 2014, os critérios antigos de distribuição de participações petrolíferas entre estados e municípios são mantidos por uma decisão liminar da ministra do Supremo Tribunal Federal. ${ }^{4}$

Outro elemento de possível explicação é a maior presença quantitativa e qualitativa de órgãos de controle de despesas junto aos gestores municipais. O Ministério Público, os Tribunais de Contas, a Controladoria Geral da União, as Câmaras Municipais, além dos próprios órgãos internos de controle das prefeituras, somados à participação popular mais consciente e efetiva, contribuem para a execução orçamentária mais eficiente. A redução da dependência aos royalties e o aumento no grau de autonomia financeira e esforço tributário próprio sugerem algum incremento nos mecanismos de controle e ampliação da arrecadação própria nesses municípios, medida também exigida pelo Tribunal de Contas do Estado do Rio de Janeiro.

O Município de São João da Barra é um caso à parte. As receitas mais expressivas de royalties e participações especiais somente iniciaram a engordar os cofres municipais em 2008, após o início da produção do gigantesco campo petrolífero de Roncador sob sua área de influência marítima, ou seja, o boom do petróleo se apresenta tardiamente comparado aos demais municípios pesquisados. A conclusão a que se pode chegar é a de que este caso encontra-se no segundo momento do ciclo da dependência, pois a tentativa de equilibrar futuramente seu orçamento somente poderá ser avaliada com o passar do tempo. Outra observação a ser realizada nos dados de São João da Barra é que os investimentos do Porto do Açu até o momento, por não terem sido ainda concluídos, não foram capazes de alavancar a receita tributária própria municipal.

A questão a ser enfrentada pelas administrações municipais responsáveis pela gestão desses orçamentos milionários/bilionários resulta na percepção de que as rendas petrolíferas não podem ser consideradas como receitas tributárias normais. Os royalties e as participações especiais não deveriam, em tese, financiar indiscriminadamente a expansão de serviços públicos ou de oferta de benefícios sociais (Pacheco, 2005:6 apud Machado e Vilani, 2011:16). De fato, a entrada dessas participações no bolo orçamentário provoca certo relaxamento administrativo e ineficiência nos gastos da gestão pública municipal (Postali, 2012:113). Portanto, a necessidade de diversificação da atividade econômica local, bem como do controle 
da qualidade dos gastos com custeio (Nazareth, 2011) e também com os investimentos é de fundamental relevância para a sobrevivência financeira e econômica desses municípios.

\section{Referências bibliográficas}

ANP - Agência Nacional do Petróleo, Gás Natural e Biocombustível. Consolidação das Participações Governamentais e de Terceiros. Disponível em: <http://www.anp.gov.br>. Acesso: 16 mar. 2014.

BRASIL. Lei $\mathrm{n}^{\circ}$ 4320, de 17 de março de 1964. Estatui normas gerais de direito financeiro para elaboração e controle dos orçamentos e balanços da União, dos Estados, dos Municípios e do Distrito Federal. Diário Oficial [da] República Federativa do Brasil, Poder Legislativo, Brasília, DF, p. 2745, 23 mar. 1964. Seção 1. Retificação Diário Oficial [da] República Federativa do Brasil, Poder Legislativo, Brasília, DF, p. 3195, 9 abr. 1964.

COSTA DA SILVA, Ronaldo. Dependência orçamentária às rendas petrolíferas em municípios selecionados do norte fluminense. Dissertação (Mestrado). Universidade Cândido Mendes, Campos dos Goytacazes, 2012.

IBGE - Instituto Brasileiro de Geografia e Estatística. Censo Demográfico de 2010. Disponível em: <http// www.ibge.gov.br>. Acesso: 16 mar. 2014.

MACHADO, C. J. S.; VILANI, R. M. Análise da justiça intergeracional como princípio norteador para a destinação dos royalties do petróleo. In: ENCONTRO DA SOCIEDADE BRASILEIRA DE ECONOMIA ECOLÓGICA, 9, Brasília, 2011.

NAZARETH, P. A. Municípios do Estado do Rio de Janeiro: prosperidade em perspectiva ou riscos à frente? In: URANI, A.; GIAMBIAGI, F. (Org.). Rio a hora da virada. Rio de Janeiro: Elsevier, 2011. pp. 255-272.

PIQUET, R.; TERRA, D. A roda da fortuna: a indústria do petróleo e seus efeitos multiplicadores no Brasil. In: PIQUET, R. (Org.). Mar de Riqueza, Terras de contrastes: o petróleo no Brasil. Rio de Janeiro: Mauad X: FAPERJ, 2011.

POSTALI, F. A. S. Rendas do petróleo e ineficiências administrativas nos municípios brasileiros. Tese (Livre-Docência). Universidade de São Paulo, São Paulo, 2012.

PRADO, S. Transferências Fiscais e financiamento municipal no Brasil. Trabalho elaborado para o projeto de Descentralização Fiscal e Cooperação Financeira Intergovernamental. São Paulo: EBAP/Konrad Adenauer, jul., 2001.

SERRA, R. O novo marco regulatório do setor petrolífero brasileiro: dádiva ou maldição?. In: PIQUET, R. (Org.). Mar de Riqueza, Terras de Contrastes: o petróleo no Brasil. Rio de Janeiro: Mauad X: FAPERJ, 2011.

SERRA, R. TERRA, D. T.; PONTES, C. Os municípios petro-rentistas fluminenses: gênese e ameaças. Revista Rio de Janeiro, n. 18-19, pp. 59-83, Rio de Janeiro, dez. 2006.

TCE - Tribunal de Contas do Estado do Rio de Janeiro. Perfil dos Municípios do Estado. Disponível em: <http: www.tce.rj.gov.br>. Acesso: 16 mar. de 2014. 
